penultimate draft - please quote only from the revised, final version (forthcoming in Ratio Vol. XXII no.2/Blackwell Publishing); to request final version email me at axel[at]gelfert[dot]net

\title{
Indefensible Middle Ground for Local Reductionism about Testimony
}

\author{
Axel Gelfert \\ Department of Philosophy \\ National University of Singapore \\ 3 Arts Link, 117570 Singapore
}

\begin{abstract}
Local reductionism purports to defend a middle ground in the debate about the epistemic status of testimony-based beliefs. It does so by acknowledging the practical ineliminability of testimony as a source of knowledge, while insisting that such an acknowledgment need not entail a default-acceptance view, according to which there exists an irreducible warrant for accepting testimony. The present paper argues that local reductionism is unsuccessful in its attempt to steer a middle path between reductionism and anti-reductionism about testimonial justification. In particular, it challenges local reductionism 'from within', without appealing to anti-reductionist intuitions. By offering novel arguments to the effect that local reductionism fails by its own standards, the present paper considerably strengthens the case against this version of reductionism. Local reductionism, it is argued, fails for three main reasons. First, it cannot account for the rationality of testimonial rejection in paradigmatic cases, even though the possibility of rational rejection is thought to be of central justificatory importance. Second, it does not provide a sufficiently distinct non-testimonial basis to which testimonial justification can be successfully reduced.

Finally, local reductionism is shown to be an intrinsically unstable position, in danger of collapsing into full-fledged 'credulism' of the kind historically associated with Thomas Reid.
\end{abstract}

\section{Introduction}

At the heart of the philosophical debate about testimony lies the question of whether a belief can have positive epistemic status qua being adopted on the basis of someone's testimony, or whether testimonial beliefs, in order to be justified, must ultimately be reducible to the more primitive epistemic sources of perception, memory and inference. Both reductionism and antireductionism about testimonial justification have variously been described as the 'received view', and each boasts its own venerable philosophical ancestry. In the present paper, I shall not rehearse the traditional debate that pits (reductionist) argument against (anti-reductionist) 
counter-argument, and vice versa. Rather, I shall provide a critique of the most serious contender amongst reductionist positions, namely local reductionism, which purports to steer a middle path between several of the more extreme positions. Instead of rebutting local reductionism with appeals to anti-reductionist intuitions (as has been done before by others), I want to criticise it from within - on its own turf, so to speak. In doing so, I intend to bring into clearer focus, through a close examination of a well-entreched position in the epistemology of testimony, some of the shared assumptions and intuitions, which I take to explain the stubborn irresolubility of the reductionism/anti-reductionism debate. As I see it, both sides in the reductionism/anti-reductionism debate struggle to make sense of two very real, and - at least on occasion - rational attitudes towards testimony: the possibility of rational rejection of an instance of testimony, on the one hand, and the rationality, on occasion, of simple acceptance on trust. By overemphasising one of these reactive attitudes at the expense of the other, each side not only neglects the intuitions corresponding to the competing side; rather, I shall argue, it also stretches its own paradigm beyond the point where it is sustainable by its own standards. More concretely, even though local reductionism is being put forward as a defence of the critical powers of the recipient of testimony, along with her 'right', as it were, to rationally reject testimony when appropriate (and to accept testimony only on the grounds of positive non-testimonial evidence), the position ultimately cannot successfully meet its own goals: that is, it neither vindicates the rationality of rejection in paradigmatic cases, nor succeeds in providing a reduction of testimonial justification in such cases where, by the standards of local reductionism, acceptance would be rational.

\section{Varieties of reductionism}

Reductionism about testimonial justification is usually traced back to David Hume, who famously argued that the reason we rely on testimony is "not derived from any connexion, which we perceive $a$ priori, between testimony and reality, but because we are accustomed to find a conformity between them' $(\mathrm{X} .1: 172){ }^{2}$ On this strong reading of reductionism, any prima facie independent testimonial justification ultimately has to be eliminated by reducing it to first-hand evidence on the basis of perception, memory, and inference. Such sweeping global reductionism has gone out of fashion, but refinements of the reductionist position continue to play a prominent role in the debate. 
What all forms of reductionism have in common is their commitment to the "necessity of reduction thesis, ${ }^{3}$ :

(R-Nec.) Our epistemic right to believe what others tell us must be grounded in other epistemic resources such as perception, memory and inference.

Within the reductionist camp one can then distinguish optimists and pessimists, depending on whether they endorse, or reject, the corresponding 'possibility of reduction thesis':

(R-Poss.) It is possible to reduce the epistemic status of beliefs gathered from testimony to other epistemic resources such as perception, memory and inference. The pessimistic reductionist who considers reduction of the epistemic status of testimonial beliefs to perception, memory, and inference to be necessary (R-Nec) but regards such reduction as impossible ( $\neg$ R-Poss), will be led to reject testimony as a source of justified belief. Pessimistic reductionism thus is incompatible with what Elizabeth Fricker (1995: 394) calls the Commonsense Constraint (CC): 'that testimony is, at least on occasion, a source of knowledge'.

For the purpose of this paper, I take global reductionism to have been conclusively rebutted in the literature. The Humean project, in particular, which attempts to justify testimony inductively by appealing to first-hand observation of the "conformity between testimony and reality', suffers from insurmountable difficulties, ranging from reference class problems to the scarcity of first-hand evidence. ${ }^{4}$ Not all attempts at reduction, however, have to be global. Even if global reduction of testimony to perception, memory, and inference 'without remainder', as it were - is not possible, it may still be possible to provide a local reduction in cases of testimonial beliefs formed by a mature recipient: ${ }^{5}$

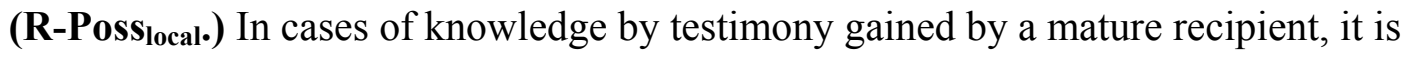
possible to reduce the epistemic status of the testimonial beliefs thus formed to other epistemic resources such as perception, memory and inference.

Initially, there is a lot that is intuitive about this modification. By referring to instances of testimonial knowledge, rather than to testimony as a category, it makes reduction a case-bycase affair, thereby avoiding the sort of immediate over-generalization that undermined the Humean attempt at global reduction. By restricting the demand for reduction to mature recipients of testimony, it allows for acknowledging our 'general and irredeemable debt to past testimony' (Fricker 1995: 404), while preserving the idea that, as mature reasoners, 'one should trust what one is told only when one has adequate evidence that the speaker is trustworthy' (Fricker 2004: 126). Thus, local reductionism steers a middle path between the acknowledgment that, for us as social beings, testimony is practically ineliminable, and the 
idea (which does not follow from the practical acknowledgment) that there exists an irreducible epistemic warrant associated with testimony that can be appealed to in any given encounter with someone's testimony. In the case of children, blind trust is clearly excusable, even necessary for their well-being, but for us as mature reasoners, different standards apply:

Does not mere logic, plus our common-sense knowledge of what kind of act an assertion is, and what other people are like, entail that we should not just believe whatever we are told, without critically assessing the speaker for trustworthiness? (Fricker 1995: 401)

In demanding a critical assessment of the evidence of a speaker's trustworthiness, for each case of testimony received by a mature reasoner, local reductionism rejects any form of presumptive right thesis, according to which the recipient, all else being equal, has a prima facie entitlement to believe what she is told. Instead, local reductionism starts from a commitment to both (CC) and (R-Nec); that is, it acknowledges that virtually all of our knowledge that goes beyond first-hand experience, and our memory thereof, is due to testimony, while remaining committed to the necessity of reduction. Given the scarcity of direct evidence for or against testimonial claims, local reductionism argues that testimonial acceptance typically requires an inference to the reliability of the testifier - testimonial acceptance must be reasoned acceptance. This aspect of local reductionism is already implicit in its rejection of the default presumptive right thesis, according to which testimony may be believed 'without any investigation or assessment', on the basis that such an entitlement 'to believe blindly [would] constitut[e] an epistemic charter for the gullible'. Indeed,

We know too much about human nature to want to trust anyone, let alone everyone, uncritically. [...W]e know too well how, and how easily, what we are told may fail to be true. (Fricker 1995: 400)

In order to avoid such failures of testimony, 'a hearer should always engage in some assessment of the speaker for trustworthiness'. (Fricker 1994: 145) The kind of activity that local reductionism requires of the recipient goes beyond the merely interpretative act of 'recognising an utterance by a speaker as a speech act of serious assertion' (Fricker 1994: 148), though, according to Fricker, the two tasks are continuous with one another:

The theme of my account is: the epistemically responsible hearer will do a bit more of the same. She will assess the speaker for sincerity and competence, by engaging in at least a little more interpretation of [the speaker]. (Fricker 1994: 148; my italics)

More specifically, 
she [=the hearer] should be continually evaluating him [=the speaker] for trustworthiness throughout their exchange, in the light of the evidence, or cues, available to her. This will be partly a matter of her being disposed to deploy background knowledge which is relevant, partly a matter of her monitoring the speaker for any tell-tale signs revealing likely untrustworthiness. (Fricker 1994: 150)

Both the active deployment of background knowledge (by which we might come to judge certain testimonial claims too implausible to warrant belief) and the monitoring of the speaker (by which we may hope to detect the speaker's intention to deceive, irrespective of the actual testimonial content) serve as 'filters', allowing only trustworthy information to pass through while rejecting potentially untrustworthy testimony. On this account, testimonial beliefs derive whatever justification they possess from the fact that they have been appropriately monitored and screened by the recipient, and that unsupported, or suspicious, testimony has been actively rejected. It is important, therefore, that instances of rejection be themselves rationally justified, and that, in rejecting a given instance of testimony, the hearer can appeal to resources - such as evidence of the speaker's insincerity - that would render such rejection rational.

Providing a defence of the rationality of rejection is crucial given the fact that local reductionism is expressly directed 'against gullibility" ${ }^{6}$, urging instead that withholding of belief may be rational more often than we would like to think. A commitment to what one might call the 'rationality of rejection thesis' (RR) is thus implicit in the local reductionist approach; however, it may also be thought of as the flipside of the commonsense constraint (CC) which local reductionism explicity endorses. After all, instances of rejection are just as much part of our common testimonial practices as instances of acceptance. Nonetheless, in light of the importance that local reductionism attaches to the duty to monitor one's interlocutors' testimony, as well as to the corresponding right to reject such testimony if it fails to meet the required standards of trustworthiness, it is worth emphasising that, either way, local reductionism must be able to account for the rational defensibility of instances of rejection.

Instances of accepting or rejecting testimony, on the local reductionist model, both depend on the hearer's assessment of the speaker's trustworthiness. In the most paradigmatic cases of testimony, we lack direct evidence for or against the content of the speaker's testimony - which is why the issue of the speaker's trustworthiness arises in the first place so active monitoring of the speaker's trustworthiness, on this account, is the only way of ensuring that our judgments concerning the acceptability of the speaker's testimony are 
supported by an adequate evidential base. The model of testimonial justification underlying the local reductionist framework is such that, on a given occasion $O$, if $H$ (the hearer) knows that $S$ (the speaker) asserted that $P$, "and she also knows that $S$ is "trustworthy" on $O$, then she has a basis justifiedly to believe that $P^{\prime}$ (Fricker 1994: 129). That is, in order to acquire a justified belief on the basis of $S$ 's testimony, $H$ must have antecedent knowledge that $S$ is trustworthy on occasion $O$. Hence, by extension, $H$ ought to accept $S$ 's testimony if and only if she takes herself to know that $S$ is indeed trustworthy on this occasion. It is important, then, to be clear about the role that local reductionism ascribes to the notion of trustworthiness. In order not to make the requirements on the hearer's antecedent knowledge too demanding, Fricker argues, the requirement of 'trustworthiness', as judged by $H$, 'should be no stronger than whatever property of $S$ it takes' to bridge 'the logical and epistemic gap between " $S$ asserted that $P$ ", and "P".' (ibid.) The hearer, thus, need not herself establish the truth, or likely truth, of what $S$ asserts on occasion $O$, but she needs to convince herself, on that occasion, 'that $S$ possesses this weakest gap-bridging property' (ibid.), in order to justify her acceptance of $S$ 's testimony. It is important to note that, while this model of testimonial justification successfully allows for the acquisition of justified testimony-based belief - i.e., if $S$ is indeed trustworthy, and is judged to be so by $H$, then $H$ can indeed learn that $P$ by accepting $S$ 's testimony - it does so by demanding that $H$ must take herself as having knowledge that $S$ is trustworthy, if her decision to accept $S$ 's testimony is to be justified. This betrays a fundamentally internalist component in local reductionism - not so much concerning the evidence for or against $P$ per se, but concerning the grounds for $H$ 's belief that $S$ was trustworthy on occasion $O$, which was a precondition for $H$ 's acquisition, in the first place, of the belief that $P$.

In summary, local reductionism demands that the justification we have for relying on testimony must be earned anew in each case, by exercising our critical abilities, 'scrutinising' our interlocutor for signs of insincerity or incompetence, 'engaging' in interpretation, 'constructing' explanations of his behaviour, and so forth. ${ }^{7}$ As these quotes show, assessing the speaker's trustworthiness, on the local reductionist account, is an achievement: testimonial justification cannot simply be assumed, but must be actively established, which typically involves an act of inference. 'Monitoring' our interlocutors and constructing an 'explanatory mini-theory ${ }^{8}$ for each new piece of testimony is crucial to this process. Assessing our interlocutor's sincerity, motives, and competence is what does the justificatory work necessary for testimonial acceptance, and it is work we do. As Fricker puts it in a more recent paper, 'the hearer's right to trust the speaker must be earned by her possession of enough 
evidence to ground an empirically justified belief that the speaker is trustworthy' (Fricker 2002: 379). Likewise, Fricker argues, even if there were an 'a priori principle of default entitlement to trust a speaker on no evidence', it could plausibly hold only in cases were it would do no justificatory work - i.e., it would simply be superfluous. (Fricker 2002: 383) Thus, against any form of a priori entitlement, local reductionism argues that the recipient of testimony must actively 'monitor' both the content and the circumstances of a given testimony, and that he is bound, on pain of violating rationality, to reject the testimony if it fails to pass the various 'monitoring' and 'filtering' procedures applied to it. While success in assessing testimony for its truthfulness is clearly important - as Fricker reminds us, 'attempting assessment, but doing it badly, is also being gulled!' (Fricker 1994: 145) - mere reliability of one's capacity to pick up on truthful testimony only (matched by rejection of suspicious or unsubstantiated testimony) is not enough: for the internalist reasons discussed above, assessments that issue in acceptance or rejection of a given piece of testimony, on the local reductionist view, must be cognitively accessible and, on reflection, rationally defensible.

\section{The incoherence of local reductionism}

In order to challenge local reductionism on its home turf, I shall offer three criticisms. First, I shall question whether rejection, as conceived by the local reductionist, can be considered rational by its own standards. In other words, I shall challenge the way local reductionism attempts to accommodate the 'rationality of rejection' thesis (RR). Second, I shall cast doubt on whether local reductionism can, in fact, achieve any significant degree of reduction; that is, I shall dispute the validity of (R-Poss local). Finally, I shall argue that local reductionism is an intrinsically unstable position, in danger of collapsing into its very opposite, namely fullfledged 'credulism'.

\subsection{The mechanisms of reduction and the problem of rational inscrutability}

For the reductionist project of grounding testimony in the more basic epistemic sources, inference is of central importance. Without it, one could not move from the narrow base of direct evidence to judgments concerning the broader conditions of the veracity of testimony. Inference also plays a crucial role in checking new beliefs against one's background 
knowledge, and in making evaluative judgments based on circumstantial evidence. Given this prominent role, it is important to ask for the nature of the inferential mechanisms by which we arrive at judgments about testimony.

According to Fricker, much of our evaluative activity 'may be automatic and unconscious' (Fricker 1995: 404): 'the specific cues in a speaker's behaviour which constitute the informational basis for this judgment [concerning the speaker's trustworthiness] will often be registered and processed at an irretrievably sub-personal level.' (Fricker 1994: 150; my italics) Much hinges on the question of whether such a conception of inferential processing is robust enough to achieve the kind of reduction that is required in order to regard testimonial justification as merely derived from more basic epistemic resources. Likewise, to the extent that local reductionism is intended as a defence of epistemic autonomy against the dangers of gullibility, it must leave room for an exercise of one's critical faculties. If our knowledge 'of what other people are like' is to be at all compelling, then we must be in a position to decide, on the basis of that 'commonsense knowledge' (Fricker 1995: 400), to withhold simple acceptance whenever it seems prudent to do so. If, however, the crucial act of monitoring is accomplished by subconscious processes, then this is not much of an epistemic accomplishment: sub-personal monitoring, strictly speaking, does not amount to any critical assessment at all, since critical judgment requires that the mechanisms and standards by which we judge be open to scrutiny - which, a fortiori, is not the case if they operate 'at an irretrievably sub-personal level'. In any case, merely positing the existence of sub-personal mechanisms does not guarantee that they are indeed sources of epistemic justification - not least because the reliability of those subconscious mechanisms that have been shown to influence affective judgments of trust in an interlocutor is hotly contested.

Fricker anticipates some of the problems arising from the rational inscrutability of subconscious judgments, yet insists that her account succeeds nonetheless in giving a 'justificationist account' of knowledge (Fricker 1994: 141) and in demonstrating that, as far as testimonial justification is concerned, “local” reduction is possible' (Fricker 1995: 403):

[I]nsisting that subjects be able to retail the details of the cues they have responded to is demanding the impossible; but we may insist, compatibly with the sub-personal character of these perceptual or quasi-perceptual capacities, that the subject's beliefs must not be opaque to her, in that she must be able to defend the judgement which is the upshot of this capacity with the knowledge precisely that she indeed has such a capacity - that 'she can tell' about that kind of thing; though she does not know how she does it. (Fricker 1994: 150; my italics) 
This passage points to an inherent instability in Fricker's account: If testimonial knowledge were only a matter of the brute reliability of 'sub-personal' mechanisms, about whose workings we must remain ignorant, then this would leave little room for the sustained defence of epistemic autonomy as which the position was originally advertised. But perhaps this conclusion is a little too hasty. After all, Fricker does insist that the subject's critical capacity, and her beliefs about it, 'must not be opaque to her' - she must be able to defend her critical assessments 'with the knowledge precisely that she indeed has such a capacity'. (ibid.) Indeed, an ability to retail reasons for the acceptance or dismissal of a given piece of testimony is crucial to epistemic autonomy: Clearly, if there is to be any strict demarcation between the mature reasoner, who exercises judgment in forming testimonial beliefs, and the gullible fool, for whom all testimony automatically issues in unreflective belief, the difference must lie in the former's ability (and the latter's inability) to rationally defend his judgments.

Given the centrality of rational defensibility for local reductionism, it is perhaps surprising not to find more of an explicit discussion of it in the corresponding literature. Fricker (1994), however, does give a few rare examples of how sub-personally derived judgments may be 'fished up into consciousness and expressed' (Fricker 1994: 150). These include such utterances as

"I didn't like the look of him";

"Well, she seemed perfectly normal". 9

One initial, though perhaps not compelling, criticism that one might raise against these examples, is that while they are indeed familiar expressions of attitudes of trust and distrust, they are hardly paragons of critical assessment and autonomous judgment. The first example in particular sounds more like the kind of lame dismissal that would prompt an impartial observer to request more specific reasons. If inferential judgments were registered at the conscious level only in such a crude way, they could hardly provide us with sufficiently robust reasons to render rejection of testimony rational - or so one might argue. An obvious set of worries in this context concerns the reliability of the kind of judgments cited: it does not take much to imagine that the dismissal of a speaker's testimony merely on the basis of a dislike of his looks ('I didn't like the look of him') may well be the result of, for example, racial prejudice.

However, apart from the empirical possibility of outright negative bias in the recipient's testimonial judgments, there are conclusive systematic grounds why local reductionism requires (or, more precisely: demands) more than a wholesale ability to 'fish up' testimonial judgments into consciousness. Recall that local reductionism attributes a highly 
specific role to judgments of trustworthiness. As discussed in section 2, in judging a speaker $S$ trustworthy (on a given occasion $O$ ), the hearer $H$ must take herself to be aware of whatever 'weakest gap-bridging property' $S$ possesses that would be sufficient to bridge 'the logical and epistemic gap between " $S$ asserted that $P$ ", and "P".' (Fricker 1994: 129) In other words, what bridges the gap between mere say-so of the speaker and truthful belief formed on the basis of the speaker's testimony, is knowledge (on the part of the hearer) of a property in the speaker - and quite specific knowledge at that. After all, whatever is the 'weakest gap-bridging property' will vary with context: in one case, it may be a speaker's proven expertise in a certain subject matter, in another case, it may be the contingent spatiotemporal position he happened to be in. Which specific ('gap-bridging') property in the speaker is material to his trustworthiness not only varies across different speakers, it will also vary for the same speaker at different instances. Even if there was such a property as general trustworthiness - perhaps conceived of as a stable character trait - judgments of trustworthiness, in the sense demanded by local reductionism, would need to be more fine-grained than that, since they need to be sensitive to the circumstances of the given testimonial occasion. (Even a generally trustworthy testifier may make honest mistakes - which the hearer may sometimes, if only occasionally, be in a better position than the speaker to spot.) Given the degree of specificity that local reductionism demands from judgments of trustworthiness, the mere wholesale ability to 'fish up' such judgments in an unspecific way is not enough to underwrite the rationality of either rejection or acceptance of a given piece of testimony.

As an important corollary it should be noted that local reductionism cannot simply appeal to self-knowledge on the hearer's part - knowledge that she is a reliable judge when it comes to assessing testimony - and let such self-knowledge take the justificatory place of specific characteristics of the speaker (i.e., indicator-properties of $H^{\prime}$ 's sincerity and competence, or lack thereof). Such self-knowledge may be one relevant factor amongst others, and may indirectly influence just how trusting, on the whole, $H$ will be with respect to the testimony of others: If one has reason to believe that one is experienced with people from all walks of life, then one may put more trust in the success of one's testimonial dealings with others, whereas if one is aware that one tends, on the whole, to be too gullible, then it will be rational to err on the side of caution. On the local-reductionist account, however, a high general level of self-trust in one's capacity as a judge of testimony is not in itself sufficient to justify acceptance of a given piece of testimony; it does not absolve the hearer from her duty, on this occasion, to 'monitor' and 'screen' the speaker for, amongst others, specific cues of possible insincerity or incompetence. Likewise, rejection of a given piece of testimony must 
be based on just such cues - i.e. on characteristics of the speaker - rather than simply on a low level of self-trust in one's capacity as a reliable judge of testimony. ${ }^{10} \mathrm{~A}$ hearer who exercises extra caution in accepting testimony, may consider a larger class of properties to be indicators of defeating conditions such as insincerity or incompetence, but she will nonetheless have to base her judgment on perceived properties of the speaker. ${ }^{11}$ Recall that what local reductionism demands is that the hearer $H$ must take herself to have knowledge of whatever specific properties make the speaker $S$ a trustworthy source. This is a significantly stronger condition than the (broadly reliabilist) demand that the hearer simply take herself to be good at picking out reliable informants. To be sure, in order to justify acceptance of a particular testimony, all that is required is for $H$ to take herself to have knowledge of relevant properties that pertain to $S$ 's trustworthiness (on this particular occasion $O$ ), but this is still different from $H$ 's merely believing herself to be a reliable detector of truthful testimony.

As it turns out, then, Fricker's own examples of how self-attributions of testimonial judgments can be verbalised ('I didn't like the look of him', 'Well, she seemed perfectly normal [to me]'), do not merely suffer from a general lack of specificity, but point to a deeper tension within local reductionism, concerning its demand for specific, and reflectively accessible, reasons for or against testimonial acceptance. This tension, I suggest, is not just incidental, but indicates an inherent instability within local reductionism: specific judgments concerning a speaker's trustworthiness simply are not so easy to come by. In particular, ascertaining which property is the weakest 'gap-bridging' property (in the sense discussed earlier) may take considerable work, which cannot easily be brushed aside with self-confident assertions concerning one's own capacity as a reliable detector of truthful testimony. Yet it is such specific reasons that, on the local reductionist model, must ultimately justify instances of testimonial acceptance and rejection.

In responding to this challenge, the local reductionist has two possible comebacks available to him. However, as I shall argue, both of these would require modifications of his account that would render local reductionism deeply unattractive. First, the local reductionist might argue for an asymmetry between positive reasons (i.e., reasons for accepting a given testimony) and negative reasons (i.e., reasons for testimonial rejection). In particular, he might argue that only positive reasons - those that support the speaker's trustworthiness - need to be specific (in the sense of bridging the 'logical and epistemic gap' between $S$ 's say-so and $H$ 's truthful belief), whereas negative reasons - those that would defeat $S$ 's trustworthiness - may be quite global. This way it might be possible to legitimize wholesale dismissals of broad classes of testimony, on the basis of epistemically unspecific criteria, such as the appearance 
of the speaker or his subjective effect on the hearer ('I didn't like the look of him'). However, it is worth considering that, on any such asymmetric account, in order to make a positive case for accepting a particular piece of testimony, one would have to disprove global defeaters on the basis of specific positive reasons in support of the speaker's trustworthiness. Given the generality of conceivable defeating conditions, this would likely be an uphill battle in many cases, and would de facto make rejection of testimony the default epistemic position. This would make testimonial acceptance extraordinarily restrictive - so much so that local reductionism would have trouble satisfying the 'commonsense constraint' (CC) it endorses: namely, the recognition that many of our testimony-based beliefs do, in fact, qualify as knowledge. Perhaps that is a price worth paying by the reductionist, but it would certainly mean a return to a 'hard-nosed' form of (perhaps Humean) reductionism, rather than a defence of local reductionism, which, after all, originally set out to vindicate the commonsense constraint (CC).

Rather than positing an asymmetry between positive and negative reasons, an alternative response to the criticisms above would be for the local reductionist to drop the demand for reflectively accessible (positive or negative) reasons altogether, instead opting for a broadly reliabilist picture. Note, however, that such an account requires significant modifications of the original framework of local reductionism. In particular, it erodes the distinction between mere reliability and the stronger demand for epistemic responsibility in forming testimony-based beliefs. Recall that local reductionism puts great emphasis on the active 'monitoring' and 'scrutinising', and demands that 'the epistemically responsible hearer will do a bit more of the same', that is, that '[s]he will assess the speaker for sincerity and competence, by engaging in at least a little more interpretation of [the speaker]'. (Fricker 1994: 148) A gullible hearer who never engaged her capacities to monitor and scrutinise a speaker would, on this account, be epistemically blameworthy, even if she happened to be immersed in a pool of truthful and competent interlocutors: such brute reliability would not suffice to vindicate gullibility as a legitimate epistemic strategy, given that, as mature reasoners, we can - and therefore ought to - take extra steps to reflect on the reasons that should underwrite our testimony-based beliefs. This deontological dimension of local reductionism - nicely captured by Fricker's (1994) slogan 'Against Gullibility' - would be lost entirely in any proposed turn towards brute reliabilism. If anything, reliabilism - by granting some testimony-based beliefs a positive default epistemic status on grounds that are not reflectively available to the reasoner - should be expected to be more congenial to credulism than to any form of reductionism. ${ }^{12}$ (On this point, see also Pritchard 2004, who 
defines the term 'credulism' as referring to any philosophical position according to which, for at least some of one's testimony-based beliefs, those beliefs can be justified even though one cannot offer independent supporting grounds in their favour.) Indeed, as I will argue in section 3.3, local reductionism does eventually collapse into full-fledged Reidian credulism. For the moment it suffices to note that the way in which local reductionism attempts to square the rational defensibility of testimonial judgments with the common-sense constraint (that many of our testimony-based beliefs do indeed qualify as knowledge), leads to a first significant tension within the position.

\subsection{Doubting the 'possibility of local reduction' thesis}

As we saw earlier, local reductionism attempts to accommodate both an acknowledgment of the commonsense constraint (CC), and a commitment to the 'necessity of reduction thesis' (R-Nec). It is central to the coherence of this project that such reduction not only be possible, but that it also succeed in deriving adequate epistemic justification of one's testimonial beliefs from the more basic epistemic sources. Local reductionism, after all, is a form of reductionism about testimonial justification, and the justification for accepting a testimonial claim must ultimately be sufficiently non-testimonial in character. This is essentially what underlies the 'possibility of local reduction thesis' (R-Poss local $_{\text {lit }}$ ).

Unlike global reductionism, which aims at a complete reduction to non-testimonial grounds for belief, local reductionism allows for the use of beliefs acquired from past testimony in assessing new instances of testimony. The credo of local reductionism may thus be summed up as follows:

Acknowledging my general and irredeemable debt to past testimony, I may nonetheless want to trust no new informants unless I have grounds to believe them trustworthy. [...] My reliance on a particular piece of testimony reduces locally just if I have adequate grounds to take my informant to be trustworthy on this occasion independently of accepting as true her very utterance. (Fricker 1995: 404)

With regard to the nature of this 'general and irredeemable debt to past testimony', it seems safe to interpret the phrase by way of contrast with the earlier reference to 'adequate grounds' required for local reduction. ${ }^{13}$ Which grounds qualify as 'adequate'? To a first approximation, such grounds must be empirical in character, though Fricker herself notes that ' $[\mathrm{w}]$ hether and how often one allows that there are empirical grounds for taking a speaker to be trustworthy depends on what one takes as constituting that'. Fricker rightly rejects Humean global 
reductionism on the basis that the latter mistakenly assumes that a 'testimony-free beliefbase' (Fricker 1995: 402) can be isolated, to which testimonial beliefs must be globally reducible. Yet, some non-testimonial empirical grounds must surely also be appealed to in any local reductionist justification of a given testimonial claim, if local reductionism is to qualify as a form of 'reductionism' at all. Hence, it seems fair to hold that, at the very least, local reductionism must demand that, in each case of justified testimonial acceptance, our grounds for belief must include some that are non-testimonial in character, even if these cannot be isolated from the rest.

In order to achieve the justificatory reduction of testimonial knowledge and thereby vindicate his commitment to (R-Poss local $_{1}$ ), the local reductionist posits the kind of inferential mechanisms discussed in the previous section, whose function it is to 'monitor' the interlocutor for 'tell-tale signs' of incompetence and insincerity. The existence and observability of such tell-tale signs, in one form or another, is central to local reductionism in general, but, as we shall see, it is also a crucial weakness. Despite its centrality, the notion of 'tell-tale signs' is left largely unspecified. In the case of face-to-face interactions, certain facial expressions, behavioural cues, mannerisms etc. would be the most natural candidates as indicators of the testifier's reliability. The question then arises how we are to recognise telltale signs as such. There are two options: First, we may be equipped with an innate recognitional capacity (or a rigid set of such capacities) that allows us to interpret, say, the fake smile of an overeager sales assistant as a natural sign of insincerity; or second, the capacity to interpret some behavioural cues as signs of incompetence or insincerity may be an acquired ability. The first option raises the question of how flexible we are in adapting our habitual response to testimony; some consequences of an overly rigid view of how we evaluate testimony will be explored in the next subsection. Here, I shall comment on the second view, according to which recognising tell-tale signs of incompetence and insincerity is an acquired ability.

The acquisition of an ability to spot liars and incompetents can take several forms. First, some criteria for what should count as a relevant tell-tale sign could be taught directly, i.e. through testimony - perhaps similar to the way that parents teach their children not to trust in certain situations (e.g., not to trust the stranger who offers them sweets). To the extent that such maxims of when and whom to trust, and what tell-tale signs to look out for in testimonial encounters, involve accepting the testimony of others before independent mechanisms of monitoring are in place, it is clear that they do not succeed in establishing a testimony-free base of independent empirical evidence. At the very least, they need to be 
supplemented with (and, depending on the degree of reduction that one aims for, perhaps eventually be supplanted by) independently acquired criteria for assessing testimony. That it is indeed possible to develop heuristics for the acceptance of testimony, based on low-level generalisations on the basis of past experience, seems obvious. What is less obvious is that such individually acquired rules of thumb can meet the local reductionist demand for a meaningful reduction of testimonial justification to the more basic epistemic sources of justification (even taking into account local reductionism's acknowledgment of our 'irredeemable debt to past testimony'). Consider how maxims and criteria for assessing testimony could have been acquired individually, as opposed to through explicit instruction. First, we may have come to notice certain regularities on the basis of direct comparison of individual testimonies with reality. Second, certain strategies of accepting testimony may have come to be seen as legitimate on the basis of their indirect success, in the sense that, while the corresponding testimonies have not been checked directly against the facts, the testimony-based beliefs they have resulted in have been indirectly corroborated through the success of those actions and subsequent beliefs which, in turn, they have played a part in. Let us call the first scenario the Direct Comparison (DC) case, and the second the Tacit Confirmation (TC) case. ${ }^{14}$ The question then is whether either DC or TC can establish adequate grounds on which future testimonial judgments can be based in a non-circular, reductionist way. Both DC and TC fail on this score, though for different reasons. DC can easily be recognised as structurally identical to Humean reductionism: where Humean reductionism demands that we ascertain the 'conformity between testimony and reality' for all kinds of testimony that we encounter, DC merely modifies this demand by asking that we check for conformity between potential indicator-properties ('tell-tale signs') and the truthfulness (or absence thereof) of the testimony we receive. However, unless one believes that there is a privileged class of 'natural signs' that qualify as tell-tale indicator-properties (an option that will be discussed in the next subsection), DC will be subject to the same fatal objections - amongst others, the reference class problem and the relative scarcity of first-hand evidence - as Humean reductionism, whose fate local reductionism set out to avoid. At first sight, TC may seem more attractive than DC, if only because it makes the validation of testimonial practices a more passive affair than DC: certain criteria of assessing testimony acquire justification as the result of the tacit confirmation that manifests itself in the continued success of actions and subsequent beliefs that we have formed on the basis of the corresponding testimony-based beliefs. However, while no doubt an element of tacit confirmation is present in our actual testimonial practices, such indirect validation does not 
help the local reductionist in identifying a stable reduction base. Given the time lag between the acquisition of many of our (perhaps more theoretical) beliefs and future instances of indirect confirmation, the TC model does not succeed in giving us (non-testimonial) grounds for accepting the initial testimony in the first place. Also, given that tacit confirmation should become more persuasive the more evidence an epistemic agent has at his disposal, the TC view does not sit well with local reductionism's emphasis on a developmental phase early on in an agent's epistemic life. The underlying reason why TC does not help resolve the theoretical difficulties of local reductionism, is that it is really too coherentist in spirit for it to support a form of (even weak) reductionism. Perhaps significantly, one of the most outspoken defenders of tacit confirmation as playing a significant part in our epistemic lives, notes that, as far as testimony is concerned, tacit confirmation really supports an anti-reductionist model of testimonial acceptance: 'Our background beliefs supply enormous empirical support for the acceptance of testimony. No additional specific evidence concerning the informant is necessary to warrant the acceptance.' (Adler 2002: 159; my italics.)

Even if one were to concede to the local reductionist that criteria for assessing testimony may be acquired in a non-circular, non-testimonial way - however tentatively or indirectly - local reductionism maintains that this process comes to an end, once an epistemic agent has reached 'epistemic maturity', from which point onwards all future speakers we encounter, along with their respective testimonies, must be 'monitored' and 'assessed' in the light of those criteria. This is precisely the reason for positing the existence of an identifiable 'developmental phase', during which, as Fricker acknowledges, '[s]imply-trusted testimony plays an inevitable role in the causal process by which we become masters of our commonsense scheme of things' (Fricker 1995: 403). Part of the intrinsic instability of Fricker's position, then, lies in the difficulty of drawing a line between the 'developmental' stage, during which we are taught a fixed set of 'tell-tale signs', and the 'mature' phase of testimonial acceptance characterised by inferential 'monitoring' based on these acquired indicators. The clearer this distinction, the easier it will be to show that reliance on 'simplytrusted testimony' is not open-ended but confined to a small enough set of claims to be acceptable to the local reductionist. Unfortunately, it is by no means clear how the distinction is to be drawn - whether by age, level of epistemic attainment, or expertise.

The problem is not merely one of vagueness concerning the degree of maturity that is required; nor is it merely a problem of individual developmental differences and variations in overall experience between different recipients. To be sure, such differences and variations do exist, and they can be expected to complicate the search for an empirically adequate account 
of existing testimonial practices. The philosophically more significant problem, however, lies elsewhere: it concerns the fact that, no matter how lax one's construal of the maturity condition, no single developmental phase can provide both a unique reduction base, and rules of reduction that are independent of, i.e. remain constant in the face of, future testimony. This point can be illustrated in two ways. First, it should be recognised that testimonial maturity, conceived of as a state of having acquired the ability to pick up on all the relevant features of a testimonial encounter, is no more than an umbrella term for a range of conceptually distinct capacities. Given the multiplicity of potentially relevant factors, active assessment of testimony, as demanded by local reductionism, might take any number of forms: a hearer might bring her background knowledge to bear on the plausibility of a claim, or she might monitor the speaker for behavioural cues, or she might construct 'explanatory mini-theories' that involve conceivable motives for deception on the speaker's part. Any instance of testimony can be classified - in any number of ways - by subject matter, kind of speaker, situational context, or by other considerations. Given that local reductionism accepts that this generates reference class problems, which prove to be fatal to the global-reductionist project of inductively establishing (from a third-person perspective, as it were) the reliability of testimony, it is difficult to see how the inductive (first-person) acquisition of criteria for reducing testimony could avoid similar problems - let alone how it could be successfully concluded within a (finite) developmental phase.

The second way of illustrating how stipulating the existence of a singular developmental phase constitutes an illegitimate idealisation on the part of local reductionism, concerns the episodic nature of epistemic competence. Criteria that were once reliable, may lose their validity - especially given the conventional and ever-changing nature of many testimonial interactions. Perhaps more importantly, however, broadly 'developmental' phases occur throughout our epistemic lives: consider receiving training in a new academic field, acquiring expertise on a topic, learning a new language or technical vocabulary, or immersing oneself in a new cultural environment. In each of these cases, and many more that involve epistemically less radical modifications, an agent will have to acquire new epistemic standards and criteria of trustworthiness, and it seems neither realistic nor possible that one's grounds for trusting the new testimony in such cases could be reduced by, and assimilated to, previously acquired criteria and heuristics. The distinction that local reductionism proposes, between a phase of 'testimonial minority' and a 'mature' phase, thus appears to be a matter of theoretical fiat, or at least the result of an unwarranted idealisation. 
The fundamental flaw in local reductionism's attempt to co-opt a developmental account is that it confuses temporal priority with justificatory significance. This results in local reductionism overlooking that criteria for assessing testimony are subject to continuous revision, and that such revision often requires taking new testimony on trust. (This point will be taken up in more detail in the next subsection.) Whatever criteria one happens to have acquired during a given, temporarily stable episode in one's epistemic life, may, to be sure, have a defeasible prima facie legitimacy, but they do not furnish the kind of stable reduction base and associated principles that local reductionism demands.

\subsection{Adaptive flexibility and the collapse into credulism}

Any successful reduction requires the existence of a stable reduction base-something the more complex phenomenon can be reduced to. In the case of local reductionism about testimonial justification, this leads to an unfavourable trade-off between, on the one hand, the adaptive flexibility of the recipient's response to testimony and, on the other hand, the degree and depth of reduction that is achievable. On the one hand, it only makes sense to speak of 'reduction' of testimonial justification if the demarcation between the formative developmental stage and the mature inferential phase is sufficiently well-defined. In order for reduction to be achieved, those inferential maxims and rules of reduction that govern testimonial acceptance must, as it were, be sufficiently robust, so that the outcome of the judgment on any given occasion during the 'mature' phase does not itself significantly change their character. (Otherwise it would be difficult to see what 'reduction' would amount to in the absence of stable reduction rules.) On the other hand, any such rigid demarcation between a developmental phase when criteria for judging testimony are acquired, and a mature phase during which such criteria are being applied, appears to preclude later adjustment of one's maxims of assessing testimony. This is clearly an undesirable consequence for any account of testimony, and of epistemic interdependence more generally. The possibility of learning from others, which the local reductionist endorses in the form of the commonsense constraint (CC), should not only extend to 'first-order' learning of individual facts, but should also encompass 'higher-order' learning of new ways of inquiry and epistemic conduct. As an example, consider the case of prejudice - racial, social, or otherwise relating to an interlocutor's identity. Others may rightly criticise us for adopting the wrong kind of criteria, or for applying double standards, when our judgments of an interlocutor's testimony are unduly influenced by aspects of the speaker's social, racial, or cultural identity. Dismissing another's word because 
of factors that are manifestly irrelevant to his standing as a good informant, would be inflicting an epistemic injustice upon him. ${ }^{15}$ In the case of testimony, the speaker sustains a testimonial injustice 'if and only if she receives a credibility deficit owing to identity prejudice in the hearer' (Miranda Fricker 2007: 28). Not only would such an 'identityprejudicial credibility deficit' demonstrate a moral shortcoming on our part as recipients of the interlocutor's testimony, it would also be detrimental to our own rational epistemic goals. Hence, it would be in our own best epistemic interest to eliminate prejudice and adjust our testimonal response in the light of criticism by others who point out such prejudice to us. However, for such correction in the light of criticism to be effective, thereby leading us to adjust our epistemic habits, may require both simple acceptance of criticism and temporary suspension of the criticised criteria of testimonial assessment. This requires restoring in the recipient of testimony what Miranda Fricker has described as the epistemic virtue of 'Reflexive Critical Openness', by which the hearer 'reliably succeeds in correcting for the way testimonial performance can be prejudiced', for example due to 'the inter-relation of the hearer's social identity and the speaker's social identity'. (Miranda Fricker 2003: 154) However, given that such openness can only be successfully be brought about by the recipient of the testimony himself, any account of testimony that takes the danger of epistemic injustice seriously must allow for considerable flexibility in the recipient's criteria for judging testimony, and for the principled revision of such criteria in the light of warranted criticism.

A virtue-based approach to testimony is, of course, quite alien to any traditional form of reductionism, and the desideratum of higher-order correction cannot easily be absorbed by local reductionism. There are two ways one could try to amend the local reductionist project in response to these criticisms: One could either postulate an (indefinitely) prolonged 'developmental' phase (or, as outlined in the previous subsection, repeated such phases), during which simple acceptance of testimony on trust is permissible, or one could introduce a demand for 'self-monitoring' (e.g., for the lack of Reflexive Critical Openness) alongside the monitoring of one's interlocutors. Perhaps these are feasible, or even plausible, philosophical projects, but they bear little resemblance to the kind of local reductionism that defines itself in opposition to anti-reductionist default acceptance views of testimony.

This brings us back to the first of the two options mentioned in the previous subsection, namely the option of regarding the capacity to recognise 'tell-tale signs' of insincerity and incompetence as innate. This is deeply problematic: for one, it is doubtful whether innate interpretative mechanisms would necessarily be optimised for epistemic reliability. However, even granted the existence of such mechanisms, this would hardly 
amount to any strong defence of inferentialist reductionism as opposed to a presumptive right or direct acceptance view of testimony. There is, on the contrary, more than a passing resemblance between postulating innate sub-personal inferential mechanisms and claiming, as Thomas Reid did, that testimonial exchanges are governed by principles 'implanted in our natures' by ' $[\mathrm{t}]$ he wise and beneficent Author of nature, who intended that we should be social creatures' (VI: xxiv). In fact, the very same 'tell-tale signs' which the 'monitoring' mechanisms postulated by inferentialist reductionism are supposed to latch on to, also form the basis of Reid's 'credulist' view of testimony: 'When we begin to learn our mother tongue, we perceive by the help of natural language' (VI: xxiv), where, in Reid's terminology, 'natural language' refers to such indicators as 'gestures, facial expressions, and [...] tone of voice' (Wolterstorff 2001: 170). The parallel extends even to the proposed distinction between a 'developmental' and a 'mature' phase of testimonial acceptance. As Reid argues:

Reason hath likewise her infancy, when she must be carried in arms: then she leans entirely upon authority, by natural instinct, as if she was conscious of her own weakness [...]. When brought to maturity by proper culture, she begins to feel her own strength, and leans less upon the reason of others; she learns to suspect testimony in some cases, and to disbelieve it in others; and sets bounds to that authority to which she was at first entirely subject. But still, to the end of life, she finds a necessity of borrowing light from testimony [...]. (VI: xxiv)

The only part of this quote that one could imagine Fricker to take issue with is the claim that testimony remains constitutive of rational authority 'to the end of life'. According to Fricker, the constitutive part of testimony is restricted to a well-defined early 'developmental phase', yet as we saw earlier it is this very restriction which severely impairs the possibility of rationally adjusting, in the light of warranted criticism and correction by others, one's habitual response to testimony.

\section{Conclusion}

The result of our analysis of local reductionism may seem negative throughout, in that no alternative account of testimonial justification has been offered. Indeed, the novelty of the present argument consists not in providing an alternative to local reductionism but in challenging local reductionism on its own turf. Whereas other authors have defended antireductionist intuitions, along with versions of the presumptive right thesis, against the critical 
demands of local reductionism ${ }^{16}$, I have argued that local reductionism is unsuccessful by its own standards: it fails both as a defence of the mature knower's critical faculties against the dangers of gullibility, and as a form of reductionism. While it has sometimes been suspected that local reductionism may not be a true version of reductionism, it has rarely been noted just how far local reductionism collapes into 'credulism' of the kind that traces its philosophical ancestry back to Thomas Reid. ${ }^{17}$ The present paper suggests a fundamental reason why such a collapse should occur. Local reductionism, originally devised as a defence of one paradigmatic attitude towards testimony - rational rejection - overshoots the mark, in that it tries, at the same time, to absorb the alternative attitude - trusted acceptance - into its theoretical framework. In doing so, however, it undermines its own theoretical commitments. The lesson, then, is perhaps this: both positions - the trusted acceptance view and the defence, attempted by local reductionists, of the possibility of rational rejection - capture very real aspects of our testimonial predicament, yet it may not be possible to assimilate them into one unitary philosophical position. Interestingly, however, this does not rule out reductionism and anti-reductionism per se: there may still be room for hard-nosed reductionist and antireductionist accounts - where such an account would not follow the conventional way of trying to square our competing, and very real, intuitions about testimonial acceptance (or of trying to assimilate them to one another), but would instead advocate that one attitude whether it be blissful gullibility or thoroughgoing scepticism - should trump all the others.

\section{Acknowledgments}

Earlier versions of this paper were presented at the Department of Philosophy, National University of Singapore and the Institut für Philosophie, Freie Universität Berlin. I am grateful to the audiences on both occasions for helpful suggestions and stimulating discussions. An anonymous referee for this journal provided exceptionally helpful comments and constructive criticism, for which I am very grateful. 


\section{Bibliography}

Adler, J.E. (2002). Belief's Own Ethics. (Cambridge, Mass.: The MIT Press)

Burge, T. (1993). Content Preservation, The Philosophical Review 102, 457-488

Coady, C.A.J. (1992). Testimony: A Philosophical Study. (Oxford: Clarendon Press)

Faulkner, P. (1998). David Hume’s Reductionist Epistemology of Testimony. Pacific Philosophical Quarterly 79, 302-313

Fricker, E. (1987). The Epistemology of Testimony. Proceedings of the Aristotelian Society (Suppl.) 61, 57-83

Fricker, E. (1994). Against Gullibility. (In B.K. Matilal \& A. Chakrabarti (Eds.), Knowing From Words (pp. 125-162). Dordrecht: Kluwer)

Fricker, E. (1995). Telling and Trusting: Reductionism and Anti-Reductionism in the Epistemology of Testimony. Mind 104, 393-411

Fricker, E. (2002). Trusting others in the sciences: a priori or empirical warrant?. Studies in History and Philosophy of Science 33, 373-383

Fricker, E. (2004). Testimony: Knowing Through Being Told. (In I. Niiniluoto, M. Sintonen \& J. Woleński (Eds.), Handbook of Epistemology (pp. 109-130). Dordrecht: Kluwer)

Fricker, M. (2003). Epistemic Injustice and a Role for Virtue in the Politics of Knowing. (In M. Brady \& D. Pritchard (Eds.), Moral \& Epistemic Values. Oxford: Blackwell)

Fricker, M. (2007). Epistemic Injustice: Power and the Ethics of Knowing. (Oxford: Oxford University Press)

Goldberg, S.C. (2008). Anti-Individualism: Mind and Language, Knowledge and Justification. (Cambridge: Cambridge University Press)

Hume, D. (1748). An Enquiry Concerning Human Understanding. Ed. by T. L. Beauchamp, 1999. (Oxford: Oxford University Press)

Insole, C. (2000). Seeing Off the Local Threat to Irreducible Knowledge by Testimony. The Philosophical Quarterly 50, 44-56

Pritchard, D. (2004). The Epistemology of Testimony. Philosophical Issues 14, 326-348

Reid, T. (1764). An Inquiry into the Human Mind. Ed. by D. R. Brooks 1997. (Edinburgh: Edinburgh University Press)

Shogenji, T. (2006). A Defense of Reductionism about Testimonial Justification of Beliefs. Noûs 40, 331-346

Weiner, M. (2003). Accepting Testimony. The Philosophical Quarterly 53, 256-264

Wolterstorff, W. (2001). Thomas Reid and the Story of Epistemology. (Cambridge: Cambridge University Press) 
${ }^{1}$ To mention just two recent examples, Faulkner (1998: 311) writes that 'anti-reductionism is by far the most common epistemological position', whereas Shogenji (2006: 332) argues that 'the more traditional position is reductionism'.

${ }^{2}$ For a clear exposition of Hume's reductionist epistemology of testimony, see Faulkner (1998).

${ }^{3}$ See Fricker (1995: 394).

${ }^{4}$ See Coady (1992), especially ch. 4.

${ }^{5}$ This formulation follows Insole's summary of Fricker's position as outlined in (Fricker 1987; 1994; 1995); see (Insole 2000: 45-48).

${ }^{6}$ See the title of Fricker (1994).

${ }^{7}$ All quotations from Fricker (1995: 404-5).

${ }^{8}$ Fricker (1995: 405).

${ }^{9}$ ibid.

${ }^{10}$ This does not preclude that there may be pathological cases, where lack of self-trust does provide rational grounds for rejecting testimony, but I take it that such cases will be few and far between.

${ }^{11}$ Of course, such properties must be relevant to the truth or truthfulness of the testimony or testifier in question; not just any property of the speaker will do: Consider the case of Bernard Black, the misanthropic protagonist of British TV series Black Books, who dismisses the testimony of a contractor he has hired by arguing 'I don't trust him - he has no nasal hair!'

${ }^{12}$ Sanford Goldberg (2008: 160) notes a similar affinity, when he argues that reliabilist considerations tend to support the kind of 'presumption-to-trust' thesis, which Fricker (1994: 128) had earlier identified as incompatible with local reductionism.

${ }^{13}$ Some indication of what is meant may be gleaned from an earlier passage, where Fricker muses that, if 'our conceptualising framework is itself socially determined', then there may be no beliefs at all 'which are not in some way contaminated by dependence on past simply-trusted testimony'. (Fricker 1995: 402)

${ }^{14} \mathrm{I}$ am borrowing the phrase 'tacit confirmation' in relation to testimony from Jonathan Adler, who develops the idea in detail in his (2002).

${ }^{15}$ This line of argument has recently been systematically developed by Miranda Fricker, in her (2007).

${ }^{16}$ E.g., Insole (2000) and Weiner (2003).

${ }^{17}$ Pritchard (2004), while recognising that local reductionism accords some testimonial beliefs (specifically, those acquired during the developmental phase) a default epistemic status, and in this sense may be regarded as a form of 'credulism', does not elaborate on the consequences I have sketched. 